\title{
Mutual Caring-Resolving Habituation Through Awareness: Supporting Meaningful Learning From Projects
}

\author{
Kam Jugdev, Faculty of Business, Athabasca University, St. Albert, Alberta, Canada \\ Paul Wishart, Faculty of Medicine, University of Calgary, Calgary, Alberta, Canada
}

\section{ABSTRACT}

This study used Grounded Theory methodology and developed an emergent theory of Mutual Caring. The main concern was Habituation to ineffective lessons learned sharing practices. Habituation is resolved through Mutual Caring, a socially and psychologically adaptive process. Mutual Caring involves comfortable conversations, engaging/sharing, and developing self-confidence, resulting in an enhanced wisdom pool. This paper extends the emphasis on tangible knowledge-sharing mechanisms. Mutual Caring could lead to better outcomes, such as more accessible and usable knowledge, a project management wisdom pool, and criteria for improved dyadic relationships to enhance project learning.

KEYWORDS: GroundedTheory; lessons learned; project management; project reviews

This article is dedicated in honor of Dr. Francis Hartman (Professor, Project Management Specialization, Civil Engineering, Schulich School of Engineering, University of Calgary) who passed away on March 16, 2014. Dr. Hartman was Kam's M. Eng. Supervisor. Francis was a charismatic, dynamic, and creative person. He was an insightful and caring mentor. He will be dearly missed.

Project Management Journal, Vol. 45, No. 2, 66-82 (C) 2014 by the Project Management Institute Published online in Wiley Online Library

(wileyonlinelibrary.com). DOI: 10.1002/pmj.21406

\section{INTRODUCTION}

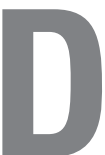

escribed as socially constructed, the discipline of modern project management emerged in the 1950s with tools and concepts spanning design reviews, configuration management, and PERT scheduling, to name a few (Morris, 2013). These days, project management involves processes based on various tools, techniques, and knowledge-based practices to meet organizational goals and to deliver products and services to the client's satisfaction (Project Management Institute, 2013). Projects are fast-paced and involve high levels of uncertainty and risks, with the majority of the team's effort and budget being expended during the execution phase (Larson \& Gray, 2014). With the priority on "doing" project tasks, taking the time to reflect and learn from project experiences understandably receives less focus. When smaller project mistakes and problems are ignored or addressed ineffectually early in a project, the errors become cumulative and magnified, adversely affecting personnel, budget, and scheduling, resulting in costly delays and rework. This contributes to a lack of forthrightness in sharing lessons learned, if reviews are even conducted. Cursory, routinized, and shallow approaches to lessons learned, coupled with the lack of effective learning on and between projects, are problematic and result in individuals independently taking piecemeal lessons learned forward to their next project; hence the term knowledge drain.

There is much project management literature on the topics of lessons learned (Williams, 2008), communities of practice (Bresnen, Edelman, Newell, Scarbrough, \& Swan, 2003), knowledge management (Liebowitz \& Megbolugbe, 2003), and learning (Sense \& Badham, 2008). Many project management practices involve codified knowledge and structured knowledge-sharing practices, yet there is limited project management literature on informal knowledge-sharing practices.

Workplace learning involves both experiential and tacit knowledge sharing. As such, project management is learned experientially. Over time, ineffective workplace learning, including learning related to lessons learned, can contribute to employee disengagement. From the organizational and human resources perspectives, employee disengagement (apathy) and withdrawal are serious concerns that negatively affect productivity, efficiency, and effectiveness. Employee detachment takes its toll on morale and motivation, which in turn, negatively affects meeting organizational objectives, let alone project goals. It is appropriate to examine workplace learning literature and how knowledge and learning are shared, because project management involves collecting and sharing considerable tacit knowledge.

As identified in the project management literature, our initial area of focus was on the knowledge drain-the descriptive and ineffective learning 
practices resulting in knowledge hoarding, limited sharing, and superficial lessons learned practices. At the start, our preliminary research question was to examine how project-related learning occurred within and between projects.

We began the study assuming that project management literature would provide a conceptual understanding of the project management learning and sharing process. Prior to data collection, we hypothesized that there was an overemphasis on the formal, structured, and codified ways of documenting and sharing project knowledge (e.g., through project review meetings, reports, and databases). We also thought that there was merit in developing project management communities of practice whereby participants learn from presentations and informal discussions.

Understanding that analytical approaches shape research questions, attention to data, conclusions and products (Starks \& Trinidad, 2007), and that literature is data, we were mindful that our research question would also change because we were interested in developing a theory about the process involved. We note this at several points in the article. Since this was an inductive study, the final research question involved understanding the process of mutual learning: "How do project personnel resolve habituation to ineffective project learning practices?"

\section{Grounded Theory Overview}

In terms of a brief overview (Dey, 1999), Grounded Theory methodologists typically set aside existing theoretical views, which means that they do not typically examine the extant literature to allow a "substantial" theory to emerge from their data. ${ }^{1}$ The generated theory focuses on a basic social psychological

${ }^{1}$ For convention in this manuscript, when the term Grounded Theory refers to the methodology, it is capitalized but not when the term grounded theory refers to the generated theory (or product) from the data. Instead, the generated theory is capitalized. For example, in this article, we capitalize the main concern of Habituation, which is resolved by the core variable of Mutual Caring. process that reasonably explains how people interact with each other in relation to the phenomenon of interest. Data analysis involves identifying and connecting categories by constantly comparing existing and emergent concepts.

Using various data sources, such as the literature, interviews, and researcher memos, the Grounded Theory methodology enabled us to systematically generate a theory of how knowledge and learning are shared among project personnel. At the end of the analysis for conceptual patterns, the main concern and the core variable emerged from the data; hence the term emergent fit. In keeping with Grounded Theory methodology, we did not allow preconceptions of the main concern (Habituation) and core variable (Mutual Caring) to bias our analysis. For this reason, we refer to the literature on habituation and caring in the discussion.

We found that our initial concern about the knowledge drain transformed into Habituation. The main concern in the project management data was actually one of Habituation to ineffective lessons learned sharing practices. Habituation perpetuates the cycle of knowledge drain and reinforces maladaptive practices. Habituation is resolved through the core variable of Mutual Caring, whereby dyads of project personnel have comfortable conversations with each other; engage in and share insights on project issues and practices; develop self-confidence; and, in doing so, mutually enhance the wisdom pool. Mutual Caring addresses the concern of superficial and shallow lessons learned practices and contributions stemming from habituations to certain knowledge-sharing practices that enable project personnel to shield themselves from blame, responsibility, and related workplace stressors. This is not an inductive theory of mutual caring based on the theory of mutual caring; additionally, habituation is not the opposite of mutual caring in this study.

The primary contribution of this study is the generated grounded theory from project management data. This article also contributes to the methodological conversations of Grounded Theory. Researchers continue to emphasize the importance of learning in project settings and in relation to building theories (Söderlund, 2004) within project management by drawing upon management schools (Söderlund, 2002). "The principal argument is that too much effort has been dedicated to clarifying the reasons of project success and failure, while downplaying a number of important research questions that need to be discussed in order to further the knowledge about project management" (Söderlund, 2004, p. 183). Because it can be useful to examine a complex field from different perspectives, this article also contributes to the conversation on learning and sharing in projects.

Grounded Theory guided the structure and organization of this article. Because "all is data" (Glaser, 1998, p. 8) and this article used the Glaserian approach, we approached the literature as another data source. In doing so, we begin with a brief review of the literature on project resources, lessons learned, communities of practice, and situated learning theory to highlight key concepts, especially those that remained relevant by the conclusion of this study. We follow this with the methodology and the study patterns as derived from the data sources on the processes project managers use to learn from and share with each other. We then present the findings and discussion. In the discussion, we introduce several new bodies of literature that were exceptionally relevant to this study and then provide study conclusions. By taking this approach, we did not allow extant literature on caring and habituation to bias the process.

\section{Literature Review}

\section{Literature Reviewed Prior to Data Analysis}

In the course of developing a grounded theory based on data from project 


\section{Mutual Caring—Resolving Habituation Through Awareness}

managers and other data sources, the findings challenged our initial assumptions. We examined the literature in the following areas: project reviews, communities of practice, the resource-based view, and situated learning theory. The literature in these areas provided us with theoretical codes (Glaser, 1978, p. 55) and contributed to our theoretical coding (pp. 55-82). The theoretical codes from the literature deepened our theoretical sensitivity for the pertinent concepts in these areas of research, which were relevant to the emerging theory we were generating from the data. The following sections outline the literature in relevant areas and indicate the theoretical codes that emerged.

Project management is a knowledge-based discipline; yet, considerable project management literature focuses on tangible resources and codifiable knowledge, including the use of various tools and techniques geared toward project success (Aubry \& Hobbs, 2011; Aubry, Hobbs, \& Thuillier, 2007; Barczak, Griffin, \& Kahn, 2009; Besner \& Hobbs, 2006; Duarte \& Snyder, 2011; Papke-Shields, Beise, \& Quan, 2010; Patanakul, Iewwongcharoen, \& Milosevic, 2010; White \& Fortune, 2002). Project reviews are primarily a formal learning mechanism, whereby the project team and key stakeholders meet to discuss the project in terms of what went well, what did not go well, and what could be done differently (Williams, 2008). These teams typically develop codified documents. There is a tendency to hoard and limit knowledge shared at project review meetings due to company culture, a resistance to learning from others' mistakes, and the perception that knowledge is power (De Long \& Fahey, 2000; Kransdorff, 1996). In terms of theoretical codes, the project reviews literature, especially the literature on ineffective lessons learned, has deepened our appreciation of the concept of knowledge drain.

Our review of the strategic management resource-based view literature has enhanced our understanding of project management resources and knowledge as a resource. An organization's resources span financial, human organizational, physical, social, and technological categories (Barney, 2001; Barney \& Arikan, 2001; Foss, 1997; Peteraf, 1993; Wernerfelt, 1984). Simpler categorizations classify resources as tangible or intangible. Based on competitive advantage criteria (Barney, 1991; Barney, 2007; Ray, Barney, \& Muhanna, 2004), a company typically has a few strategic resources. Most strategic resources are intangible and culturally embedded (Eisenhardt \& Santos, 2000). Examples of strategic resources include knowledge, intellectual property rights, reputation, brand, and culture (Barney, Ketchen, \& Wright, 2011; Foss, 1996; O'Dell \& Grayson, 1998). Based on the resourcebased view, several project management studies have emphasized the importance of intangible resources, such as sharing know-how (otherwise known as tacit knowledge, which is shared through mentoring, stories, brainstorming, and shadowing), social capital, and communities of practice (Jugdev \& Mathur, 2006; Jugdev \& Mathur, 2012, 2013; Jugdev, Mathur, \& Fung, 2007; Mathur, Jugdev, \& Fung, 2007, 2013).

The resource-based view literature has enhanced our understanding of the distinction between tangible and intangible organizational resources and has also improved our appreciation of knowledge as an intangible resource. These theoretical codes have provided us with a fresh perspective on project reviews, by realizing that the focus was on tangible, codified, and formal project review resources (e.g., a document) compared with other more intangible resources (e.g., relationships and the value that lies within these relationships).

The lessons learned literature has also broadened our conceptualization of knowledge and has led us to examine the workplace learning literature, thus revisiting the communities of practice literature from a different perspective. Situated learning theory is a workplace learning theory (Boud \& Garrick, 1999;
Bratton, Helms-Mills, Pyrch, \& Sawchuck, 2004; Fenwick, 2006; Gherardi, 2009; Lave \& Wenger, 1991). Unlike formal or cognitive classroom learning, situated learning is embedded in practice, context, and culture (Gherardi, 2009). Relational and practice-based learning emphasizes the collective over the individual (Bratton et al., 2004), where learning is a social construct-"distributed over both individuals and their environments, and learning is situated in these relations and networks of distributed activities of participation" (Hemetsberger \& Reinhardt, 2006, p. 189).

The situated learning theory literature spans communities of practice and the concepts of knowledge and learning. Simply transferring or transmitting knowledge does not fully explain knowledge circulation, because these terms imply knowledge uniformity and do not account for how knowing and knowledge are impacted by the "imprint of interested parties, multiple activities, and different goals and circumstances" (Lave, 1993, p. 13), whereby knowledge changes through engagement with others.

Communities of practice involve "groups of people who share a passion for something that they know how to do and who interact regularly in order to learn how to do it better" (Wenger, 2004, p. 2). The skills we learn are connected to the practice in which they are located (Lundin \& Nuldén, 2007). The project management literature on communities of practice tends to be descriptive and commodifies the construct. The field usually presents a community of practice as a tangible construct at the expense of its intrinsic value (Egbu, 2004; Garrety, Robertson, \& Badham, 2004; Gongla \& Rizzuto, 2001; Kamara, Augenbroe, Anumba, \& Carrillo, 2002; Kransdorff \& Williams, 1999; Lesser \& Storck, 2001; Liebowitz \& Megbolugbe, 2003; Snider \& Nissen, 2003). In part, this stems from the field of project management having yet to interconnect fully with the workplace learning domain.

Several publications in the project management domain have intersected 
with workplace learning. Newell et al (2006) distinguished between knowledge as an entity and knowledge as a practice (2006). Sense constructed communities of practice in the situated learning theory context $(2008 ; 2003,2004$; Sense \& Bedham, 2008), proposed project teams as embryonic communities of practice (learning generators), and stressed the importance of personal and social approaches to knowledge flow (2003).

That situated learning theory literature has improved our understanding of the concept of communities of practice as being more than like-minded individuals meeting to an expanded appreciation that the concept needs to embrace the importance of (dyadic) relationships. Although we initially assumed that communities of practice would emerge as a significant variable in our data, this was not the case in the findings. This literature has also sharpened our understanding that knowledge is more than a commodity because it changes through interpersonal engagement. Situated learning theory has also broadened our understanding of learning beyond cognitive perspectives to socially constructed perspectives and enhanced conceptualization of the value of tacit knowledge.

Action learning literature has honed our understanding that learning is a multi-layered process facilitated by five values: structural, cultural, psychological, policy and leadership, and contextual facets (Lipshitz, Popper, \& Friedman, 2002; Ron, Lipshitz, \& Popper, 2006, p. 1070):

- The structural facet of organizational learning mechanisms relates to project reviews, which are institutionalized and procedural.

- The cultural facet consists of behavioral norms toward productive learning (i.e., transparency, integrity, issue orientation, inquiry, and accountability).

- The psychological facet involves psychological safety and organizational commitment to enhance sharing and risk-taking with new ideas and practices.
- The policy and leadership facet relates to management practices tolerating mistakes and job security.

- The contextual facet involves environmental uncertainty beyond managerial control.

These values align with our grounded theory, whereby the emergent theory stemmed from the structural facet (project reviews). The main concern and core variable of our theory reflect the psychological facet. The subcategories within the main concern of Habituation fit the cultural and psychological facets but in a negative way. Similarly, the sub variables within Mutual Caring fit the cultural and psychological facets positively.

Emergent fit (Glaser, 1998, pp. 104105) guided the inclusion (or not) of these theoretical codes from the various literature contexts into our emerging theory. The theoretical codes were included where relevant and not forced as part of some received theory (p. 103) or 'pet' codes (Glaser, 1978, p. 105).

\section{Methodology}

Grounded theory should be viewed as a package of research methods that includes the use of concurrent data collection and constant comparative analysis, theoretical sampling and memoing, all of which can create an awareness and an appreciation of the scientific merit required of Grounded Theory research and promote quality standards relating to research practices in Grounded Theory methodology. (Elliott \& Lazenbatt, 2004, p. 48)

This section begins with a brief overview of the methodology to guide readers on the approach. Grounded Theory originated within the interpretive tradition of symbolic interactionism (Benoliel, 1996; Blumer, 1986) and it is used in many fields, with literature also addressing methodology quality (Elliott \& Lazenbatt, 2004). "The identified theories point to the salient influences of social structure and environment on human health and well-being." (Benoliel, 1996, p. 406) Along these lines, we developed a grounded theory on Mutual Caring in project management, and in doing so, created a theory of a basic social psychological process.

The four stages of constant comparison (Glaser, 1965) involve comparing experiential narratives (incidents), creating categories, integrating categories (by identifying interrelationships and theoretical codes) (Hernandez, 2009), and delineating a substantive theory about the relationships. Constant memoing based on data sources, ideas, patterns, and personal reflections provide structure and backbone to the emerging theory. Researchers fracture data sources and any preconceived biases or worldviews to determine what is happening in the data (Glaser, 1992, 1998). Patterns emerge from the data, as do indicators of these patterns because researchers develop theoretical sensitivity for concepts. For example, during the analysis, we were already sensitized (theoretical sensitivity) to the communities of practice concept and over time developed the theoretical code of dyadic relationships. The culmination enables the identification of a core variable that is relevant and "grabs, fits, and works" (Glaser, 1978, 2001).

Theoretical saturation (Glaser, 1998, pp. 139-142) is demonstrated through the following: inclusion of multiple data sources in addition to the 15 interviews; in other words, "all is data" (pp. 8-10, 142 ) and data sources are constantly compared (Holton, 2007). These data sources included observation, the professional experience of the principal investigator, the literature, follow-up telephone calls with participants, and three new interviews after analyzing the first 15 interviews; more importantly, the constant comparisons of the codes, concepts and categories, and memoing while coding (and subsequent memo sorting), support theoretical saturation being reached. Theoretical saturation was achieved where no new concepts, dimensions, or properties emerged from 


\section{Mutual Caring—Resolving Habituation Through Awareness}

the data. Interchangeability of indicators (Glaser, 1998, pp. 141-142) is a condition for theoretical saturation or completeness as well which was met with our theory of Mutual Caring. The theory generated is of such scope that there are a multitude of indicators within the data, which can be interchanged and the theory still holds.

The core variable must have maximum explanatory power. In developing a substantive grounded theory, the researcher typically generates a basic social psychological or structural process. The theory generated from the data has to be relevant. Supporting the theory being relevant are the following: the theory has to grab, fit, work, and be modifiable. Grab refers to the theory being engaging. Fit refers to the presence of solid indicators in the data using different contexts that work (i.e., indicators from the literature and the data). A theory that works means that the grounded theory generated resolves the main concern; in other words, both the main concern and core variable are generated from the data, not preconceived. We analyzed empirical data from project managers and developed a grounded theory on Mutual Caring that could lead to better outcomes, including more accessible and usable knowledge, a project management wisdom pool, and criteria for improved dyadic relationships to enhance project learning. Not only does a plausible grounded theory have properties and dimensions, but it also transcends the context of its origins. To exemplify this, the coauthor discussed how they experienced Mutual Caring in the service of collaborative research discovery.

After securing research ethics approval from the university, we developed a set of semi-structured interview questions, which were pretested with three project management colleagues. This enabled us to make minor modifications to the questions. We trained our research assistant (who was experienced in conducting interviews) on the interviewing process and protocol we wanted her to follow. In 2010, through our network of contacts, we invited experienced project managers to participate in the study. The research assistant interviewed 15 individuals who were employed in various industries.

The lead researcher discussed the interviews with the assistant as they progressed, reviewed the transcripts upon receipt and initiated coding concurrently. The principal investigator coded the transcripts. As Glaser relates: "it is painstaking and time taking to code carefully, but the analyst must do his [their] own coding" (Glaser, 1978, p. 58). He further notes that it is easier to code another person's interviews due to the distance between the empirical view from the research context and from collecting the data. We acknowledge that individual reports involve self-report bias, a limitation that also exists with surveys.

In Grounded Theory, researchers must "let the data speak for itself" (Glaser, 2011, p. 1) so that variables earn their way into the theory (Glaser, 2002). This is in contrast to descriptive qualitative data analyses such as case studies (Yin, 2009), which traditionally include face sheet data (e.g., demographic information). Allowing variables to earn their way into the theory obviates them from being habituated to a preconceived framing of research and enables researchers to focus on variables that enhance generalizability (Roderick, 2009). Face sheet data that emerged as a relevant variable in this study pertain to age. Table 1 presents demographic information on the participants.

We imported the transcripts into ATLAS.ti (version 7), a software program for qualitative data analysis and one co-author coded and memoed the data. Coding data included identifying indicators by labeling words, phrases, and sentences. It was challenging at first to avoid the pitfall of generating descriptive codes and the burden of worrisome accuracy in erroneously thinking that the transcripts provided complete evidence. The other co-author

\begin{tabular}{|c|c|}
\hline Criterion & Results \\
\hline Gender & $\begin{array}{l}4 \text { Females } \\
11 \text { Males }\end{array}$ \\
\hline Industries & $\begin{array}{l}6 \text { - Oil and Gas } \\
4-\text { Information Technology } \\
2-\text { Utilities } \\
2-\text { Construction } \\
1 \text { - Pharmaceutical }\end{array}$ \\
\hline Age & $\begin{array}{l}2-30 \text { to } 40 \\
7-40 \text { to } 50 \\
6-50 \text { to } 60\end{array}$ \\
\hline $\begin{array}{l}\text { Years of experi- } \\
\text { ence }\end{array}$ & $\begin{array}{l}1-\text { Under } 10 \\
6-11 \text { to } 20 \\
8-21 \text { to } 30\end{array}$ \\
\hline Education & $\begin{array}{l}3 \text { - Undergraduate degree } \\
12 \text { - Master's degree } \\
3 \text { - Doctoral degree }\end{array}$ \\
\hline \multicolumn{2}{|c|}{$\begin{array}{l}\text { Note: } 12 \text { of } 15 \text { participants were Project } \\
\text { Management Professional (PMP) }{ }^{\circledR} \text { credential } \\
\text { holders. }\end{array}$} \\
\hline
\end{tabular}

was an experienced Grounded Theory researcher who facilitated the transition from description to the conceptualization of the pattern of "what was going on" in the data (Glaser, 1998, p. 4).

We memoed the data manually and used ATLAS.ti to generate 58 codes. Further analysis of the codes led us to create 23 meta-level codes, which were more abstract and conceptual. In ATLAS.ti, groundedness refers to the number of quotations to which the code is applied. The seven meta-level codes with the highest degrees of groundedness follow, with the number in brackets indicating groundedness level:

- Personal Knowledge (52)

- Selective Sharing (44)

- Information and Communication Technology (38)

- Sharing (35)

- Teamwork (34)

- Resisting (31)

- What Motivates Me (31)

As the analysis unfolded, groups of employees (demographics) emerged as a key category consisting of subcategories of senior managers, senior 
employees, junior employees, and retirees. During the analysis, we used the literature we had reviewed at the start of the study. Our iterative analysis of transcript data and literature (which was further reviewed after some significant concepts had emerged) contributed to the relevance of the emergent theory.

As expected in Grounded Theory research, our study question changed because of our immersion in the data and our questioning of what was occurring. The preliminary research question that supported this study was to examine how project-related learning occurred within and between projects. After conducting the study, the research question that this study actually focused on was: "How do project personnel resolve habituation to ineffective project learning practices?" Mutual Caring was the basic social psychological process that emerged from the analysis to resolve the main concern of Habituation. The next section presents the patterns supported by the data.

\section{Study Patterns}

Figure 1 illustrates that the main concern and core variable are connected through a transition point. These variables are elaborated on in this section.

\section{Main Concern: Habituation}

Habituation is the main concern in this study. Pushing and resisting are subordinate variables to spinning but reinforce spinning. The pattern that leads to resolving this main concern is the core variable of Mutual Caring. Awareness is a theoretical code that surfaced as mediator in the shift from the main concern of Habituation to the core variable

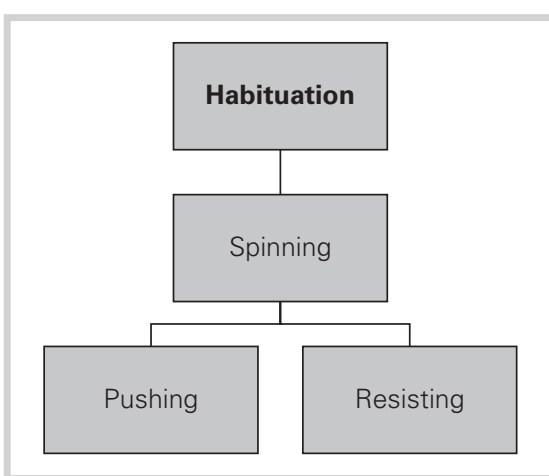

Figure 2: The main concern.

of Mutual Caring. Figure 2 depicts the core concepts of Habituation, which are discussed thereafter.

Knowledge flow conflicts between employees are evident where pushing and resisting information exchanges occur. Routinized behaviors and learning related to sharing knowledge and learning in project management are also indicators of spinning. Habituation may look and feel safe, but it is like a tire spinning in a rut without traction. Healthy and unhealthy habits both reflect ingrained patterns of behavior that can be cultivated; thus we view Habituation as involving adaptations, desensitizations, and possibly implicit learning to the point of becoming accustomed to certain unhealthy practices. Habituation is counterproductive and involves individuals unproductively focusing on their own needs and rationales to keep knowledge to themselves, which is then reflected in their practices.

Habituation is an egocentric "mefocused" condition emphasizing individualization, meaning, to protect oneself. Habituation is a defense mechanism based on psychological coping strategies used to deal with stress, anxieties, and deflect blame or responsibility. Colloquially, Habituation can be called "self-caring" and is manifested through "what's in it for me?" type practices. Self-caring is a dominant category within the main concern. Employees engage in different forms of Habituation practices by disengaging in terms of workplace productivity; they can also disengage emotionally, psychologically, and socially. When this happens, Habituation contributes to interpersonal conflict, communication problems, and further withdrawal, leading to workplace discord.

Disengaged individuals may perceive their behaviors to be helpful because the behaviors contribute to self-preservation. This perception reinforces the maladaptive behaviors of Habituation. For example, as manifested in the data, individuals discussed examples of "selectively shared" project lessons learned. Selectively sharing personal knowledge (knowledge hoarding) is widely acknowledged as an issue in the project management literature on lessons learned (Hall \& Sapsed, 2005; Kotnour \& Kurstedt, 2000) and in the management literature in relation to tacit knowledge and the implications for innovation (Leonard \& Sensiper, 1998). Over time, the habituated needs of the individual become the primary focus and involve other maladaptive and dysfunctional behaviors. In contrast to habituation, there are healthier ways of dealing with stressors and anxieties. Transitions based on awareness and a comfort level with change leads to the process of Mutual Caring, reflecting adaptive patterns of behavior and interpersonal communication.

\section{Mutual Caring}

Awareness mediates the shift from the main concern of Habituation to the core variable of Mutual Caring. Awareness involves accountability. Mutual Caring represents a shift from a "me-focus" to an "us-focus" (whereby there is more wholeness through integration).

Figure 1: The connections between the main variables. 


\section{Mutual Caring—Resolving Habituation Through Awareness}

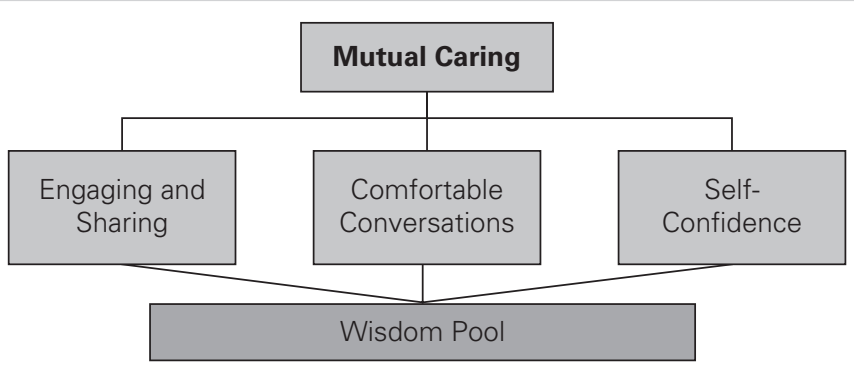

Figure 3: The Mutual Caring pattern.

Mutual Caring involves the sub-core variables of engaging in comfortable conversations with trusted advisors to discuss project management issues, concerns, and problems. As the two parties engage together and share practices (another sub-core variable), they develop self-confidence. The culmination of these mutual practices helps create an expanding wisdom pool of usable project management knowledge and learning. Figure 3 depicts the Mutual Caring pattern.

Mutual Caring signifies a shift from individualization (which is "me" based and present in Habituation) to individuation. As ascertained from the literature after the analysis, the concept of individualization spans the sociology and social psychology bodies of literature. For example, some of the literature on individualization focuses on how young adults become adults (Côté \& Schwartz, 2002; Schwartz, Côté, \& Arnett, 2005) in terms of identity formation. Individualization is marked by passive and procrastinative approaches based on default options. Individualization involves less effort and a reliance on "paths of least resistance." These young adults tend to avoid or ignore opportunities for self-improvement, for example, competences and skills; in doing so, they also tend to be less prepared in making decisions. In contrast, developmental individualization (Côté \& Schwartz, 2002) is based on exercising agency (responsibility) and it is demonstrated through initiative. Since we had not examined the sociology or social psychology literature until the end of the study, we labeled the alternate variable to individualization as individuation.

Through individuation, by using socially and psychologically adaptive practices, we remain unique and yet whole, thereby enhancing interpersonal communication. Reflecting positive caring, Mutual Caring is a healthier behavior than Habituation. Mutual Caring involves compassion. Unlike the "what's in it for me" practices evident in Habituation, Mutual Caring contributes to an expanded pool of knowledge focused on the greater good; for example, others on the team, the department or organization. Mutual Caring involves being available in terms of workplace productivity as well as emotionally, psychologically, and socially.

To offer examples of the conceptualization process, while remaining mindful that the codes can shift, we connected concepts in different ways and introduced theoretical codes:

- Individualization surfaced as the theoretical code pertaining to Habituation and self-caring.

- Spinning was promoted to the subcore variable from the category level, with pushing and resisting remaining as categories.

- Awareness, a theoretical code, surfaced as the transition point between Habituation and Mutual Caring and choice became less relevant.

- Disengagement and self-preservation became less relevant during the analysis as the core variable shifted from caring to Mutual Caring.

- Wisdom pool became an outcome indicator and was demoted from the category level.

The above examples represent aspects of the process of generating a substantial grounded theory. Detailed findings based on the main concern and core variable are presented next.

\section{Interview-Based Findings}

Personal knowledge is tacit and experiential. A number of participants referred to personal knowledge using such terms as "intellectual property" and "innate." "Cause knowledge is local and how do you spread it? That knowledge is innate. It has to be almost moved person to person" (CE, line $211^{2}$ ). Staff turnover contributes to the knowledge drain and impacts the pool of knowledge to which those employees can turn for guidance, particularly as experienced employees retire. Since socializing new employees takes time and different interpersonal dynamics exist in the workplace, this can also affect the nature of interpersonal relationships.

As a valuable source of competitive advantage, knowledge hoarding can occur due to concerns of career advancement, performance reviews, and worry that others will take credit for ideas. For example, some participants discussed fears related to "being taken advantage" of by exposing vulnerabilities. Study participants indicated that organizational politics and a lack of trust contributed to selective sharing and that the culture was not always conducive to openness and sharing. Hoarding personal knowledge reflects "what's in it for me" practices.

They're holding back from sharing, because just like a competitive advantage across companies, there could be a competitive advantage between

${ }^{2}$ Study participants are identified with pseudonym initials to ensure anonymity; the word "line" and its accompanying number refer to the line on the transcript where this was cited. 
employees. Why should I help you by giving you all this great and wonderful knowledge and then you get a promotion and I don't (SP, line 58)?

Project review meeting participation is compromised when there is a reluctance to share project mistakes to avoid shame, reprimands and, in the case of contractors, potential lawsuits and lost future business. When individuals withhold knowledge, overly sanitized project learning is shared, offering limited value.

Through the review exercise, it becomes abundantly clear that nobody wants to talk about it, because it's embarrassing for certain departments or individuals to have the issue highlighted. So everybody kind of shies away from it and doesn't focus on it. At the end, it's basically a session of-we did a good job, everybody pats themselves on the back and that's the end of it. So at the end, there's no interest. Very little learning is done by the team or organization (TS, line 39).

Exemplifying spinning, some participants spoke about the importance of succession planning and indicated that this topic was discussed repeatedly at senior-level meetings, but remained to be resolved. "And that is the gap that we're struggling to fill right now because with so many baby boomers retiring from our organization we have missed the opportunity to bridge that gap" (BJ, line 146).

In terms of the main concern of Habituation (see Figure 2), tension exists between the concepts of pushing and resisting, which contribute to spinning. Certain types of knowledge-sharing practices contributed to this tension, whereby demands and expectations of one group of employees (senior managers, senior employees, or junior employees) were met with resisting behaviors from another group of employees. This opposition of intentions results in spinning for self-preservation purposes. The findings indicated that employees weighed the amount of effort required to demonstrate a degree of compliance in relation to knowledge-sharing practices and the impact sharing it had on them personally (i.e., "what's in it for me" factors). Note that the four categories of different employee groups (senior managers, senior employees, junior employees, and retiree group) were based on face sheet data, and represent variables that earned their way into our theory.

Senior managers are responsible for decision making to ensure that project work is aligned with the corporation's mandate and business goals. As per the literature on escalating commitment (Keil \& Montealegre, 2000; Staw, 1981), some executives pushed the importance of certain pet projects or practices, despite valid reasons to terminate the project or discontinue the practices (for example, a newly customized database). Sometimes, in the interest of their own performance, senior managers pushed for compliance to project review practices by linking them to employee incentives, such as performance reviews or bonuses. "You typically ask the team to work together and then you reward them individually. And so at times they're holding back" (SP, line 55). Other senior managers advocated database use despite issues related to system and information quality. Pushing practices of this nature contributed to jaded perceptions of leaders, marginalized compliance on the parts of employees and employers, as well as the preconception that employee compliance is the issue. "Yeah, like the corporate leaders. Those are the people who are actually forcing them because a project is just a project but the corporation or organization has vaster interests (NT, line 163).

Indicators of resistance pertaining to employees and databases related to information quality, data entry, and compliance issues. Forms of resistance can be overt or covert. Those with a mandate to ensure compliance assertively pushed and advocated database use even though employee responsiveness was inconsistent and data quality was suspect. Some study participants indicated that database information was sifted by managers to determine what information was worthy of being labeled a lesson learned. This is a form of pushing to promote certain lessons over others. Other examples of resisting included participants stating they were too busy to use the databases and had concerns about database costs and design. They viewed data quality to be complaints or junk that staff entered to demonstrate cursory compliance. Tensions of this nature reflect spinning when databases continue to be used in this way. In terms of the main concern (Habituation), the next quote concisely encapsulates the three concepts of pushing, resisting, and spinning:

I call it a push and a pull for dissemination. So how do I go and pull information if all I am is frustrated even trying to open it up? I get it open and I hit something and what I get for search results are a joke (RB, line 237).

At the employee level, resistance was also evident when people were reluctant to share their knowledge; still others felt that the only way a person could learn was from his or her own mistakes. "But a lot of times people will say-I know lots of things, why do I go and chase around for more information? If it's not my own knowledge it's probably not any good" (LJ, line 62).

Face sheet data related to demographics emerged as significant in this study. Knowledge transfer between age groups may depend on the nature of the knowledge. A number of study participants indicated that they often consulted senior employees for advice. Some participants indicated that senior employees preferred to discuss matters face-to-face rather than use the technology they were expected to use. "One other challenge that occurs with our baby boomers' involvement with populating the database is that it just doesn't happen; they're not used to that" (BJ, line 202). This resistance to database 


\section{Mutual Caring—Resolving Habituation Through Awareness}

use may have been due to a lack of technical abilities or a diminished desire to learn how to use information communication technology. Other employees could be close to retirement and were either in the process of disengaging from work or had already lost interest; still other senior employees resisted learning because of their "know it all" attitude (a factor that was not an agedependent one).

Junior employees may feel threatened by senior employees and resist sharing their knowledge out of a desire to advance their own careers, perceiving themselves as having more to lose if they shared their knowledge with others. Having grown up with technology, junior employees are also more comfortable using information communication technology. Some study participants indicated that junior employees did the database work and helped senior employees with technology. "The folks that are comin' in, they're so technically savvy that they don't want to sit with a pen and paper and learn from the older folks" (BJ, line 150). In contrast to this, another participant indicated that junior employees carried less baggage and were more willing to learn compared with senior employees.

The retiree group was also unique. Interviewees indicated that the retirees worked because it helped them avoid boredom, continue to grow, develop, and stay engaged in sharing their experiential knowledge and wisdom gained with those employees who are receptive to it.

That's where those gray heads at the table matter. The more of them around, the happier I am, 'cause they will come with that luggage and I want them to have that luggage to avoid making the same mistakes on my own. And that's what the 72 year old and 75 year old definitely do. So that wisdom pool is working for us and helping us (DB, line 127).

During coding, we were struck by the concept of wisdom pool and memoed this. This theoretical code helped cultivate our theoretical sensitivity and led to the core variable of Mutual Caring. Mutual Caring is a powerful theoretical code that conceptualizes how individuals learn and share together, regardless of generational differences. By transcending age differences, the theoretical code labeled wisdom pool both illustrates transcendence of Mutual Caring as a theory and reflects an outcome of mutual caring (i.e., usable knowledge and learning).

In summary, the Habituation pattern corresponds to the concepts of vicious and virtuous cycles derived from management theory where, although the contexts pertained to entrepreneurial change (Ropo \& Hunt, 1995) or leadership change (continuous change or inertia) (Weick \& Quinn, 1999), the concept of adaptive changes over maladaptive ones still applies. Spinning reinforces the Habituation process, contributing to loss of focus, self-protective behaviors, and further disengagement. Within the Habituation process, friction arises between pushing and resisting and perpetuates the spinning process. Pushing and resisting compound and exacerbate interpersonal (and intrapersonal) conflicts, fuel communication problems, and reinforce these behaviors. Employees continue to engage in such behaviors because the routines are familiar and comfortable. The employees are habituated and convinced that remaining in this holding pattern is the right thing to do.

Habituation is a block in the road toward Mutual Caring. Initially, it appeared that the concept of choice was the transition point between Figure 2 (Habituation pattern) and Figure 3 (Mutual Caring pattern); however, through further memoing and constant comparison, which contribute to theoretical saturation (Glaser, 1965), the relationships between the codes and categories shifted. The sub-core variable of awareness emerged as a more appropriate and pivotal theoretical code in conceptualizing the transition between the two stages or behaviors leading to
Mutual Caring. Awareness that one is spinning in project management mediates the choice to shift from Habituation (Figure 2) to Mutual Caring (Figure 3) where individuals regularly seek project management guidance and knowledge. Whereas Habituation emphasizes individualization (May, Gilson, \& Harter, 2004) and self-interest, Mutual Caring emphasizes individuation and caring for others through sharing, engaging, and comfortable conversations with trusted advisors. The Mutual Caring process involves reciprocal trust and the appreciation that moving away from Habitation has merit.

The transition to Mutual Caring is not an easy one, because of the fear of change and the negative emotions and thoughts often associated with change. Some individuals may transition incompletely and revert back to Habituation. The next quote exemplifies a transition from Habituation to Mutual Caring, because it reflects the shift toward appreciating the collective benefits of knowledge sharing on projects versus hoarding it. "The other project managers are bright enough that through team success they will achieve their goals" (DB, line 359).

Another shift in the data pertained to the distinction between informal and formal knowledge transfer. Who we know, who we trust, and who we turn to for help stem from social capital theory (Coleman, 1988; Nahapiet \& Ghoshal, 1998). Several participants indicated that true project details emerged through these informal networks. "There's the formal organization and then there's the informal organization and if you find that informal organization and who really knows the history, that's how you tap into that knowledge, but it's not on an org. [organization] chart" (MA, line 231).

Our valuable and tight social networks can help identify respected and trusted advisors. Mutual Caring in project management involves working closely with a trusted advisor. The concept of trusted advisor is reminiscent of the concept 
of the apprenticeship model (Nonaka, Toyama, \& Konno, 2000). Another example of transcendence is that advising was not age-dependent. Unlike a directive supervisory style that perpetuates an unequal level of interaction, advising is a bidirectional and collaborative process that depends on who has certain knowledge, skills, or abilities to offer and the interest and willingness of another person to benefit from advising. As mutually beneficial, advising involves growth and fulfillment.

Interestingly, although one of our initial assumptions was that communities of practice were an effective way to informally share knowledge and learning, the communities of practice code did not emerge as relevant in the data analysis other than through participant descriptions of its functions. Instead, dyadic relationships did emerge as a relevant concept. What makes a person comfortable in talking with and listening to a trusted advisor? Self-confidence is necessary to having comfortable conversations. A trusted advisor is approachable and accessible, inquisitive, and caring. For Mutual Caring to occur the two parties are ideally face-to-face; there is trust, compassion, and respect, as well as a sense of safety without the need to focus on Habituation practices, such as defensiveness. The trusted advisor concept further exemplifies the transcendence of Mutual Caring. Since information can be context dependent and embedded, connecting with others can help transcend context. Sharing involves discussing context to translate project experiences so that others can interpret and understand the situation. Discussing context on a one-to-one basis helps transcend issues, such as an abridged version of project events toward more meaningful exchanges about lessons learned. The relationship with trusted advisors is based on and evolves through an informal and comfortable rapport.

When employees talk with trusted advisors, they feel safer and more comfortable. They come to understand that they are not alone in their concerns, fears, or worries about making mistakes. It is human to make mistakes and then try to hide them. A trusted advisor will often share the mistakes he or she has made in project management. Through engaging, we have opportunities to learn from trusted advisors and act upon their guidance and advice. It is important to note that, although Mutual Caring can build capacity, unless the capacity is converted into action and put to use, it lacks impact.

He literally gave me a card that says whenever, whatever you want to talk about. Here is my number, here's my cell number, here's my number at my son's office where I'm occasionally at, here's my home number and if I'm not here, check the hospital, 'cause that's about the only other place I will be (DB, line 363).

As part of the analysis, the authors also memoed the impressions of what makes us comfortable and uncomfortable in the contexts of the Habituation and Mutual Caring patterns. In terms of Figure 2 (Habituation pattern), the process of resisting and pushing for the purposes of self-preservation simultaneously evokes feelings of comfort and discomfort with our behaviors and communication practices; however, these feelings can be expressed through frustrations, disillusionments, and interpersonal conflict, which can perpetuate Habituation. Individuals also feel uncomfortable when faced with change.

The transition to Figure 3 (Mutual Caring pattern) can also elicit feelings of discomfort, but does not always preclude change because of the gains employees experience incrementally and ultimately achieve through these changes. Initially, working with a trusted advisor can be uncomfortable because it involves sharing concerns, apprehensions, and frustrations, as well as the challenge of trying something different. This type of discomfort, however, differs from the discomfort experienced in the Habituation process because it involves positive and healthy changes. Progression from the pattern of Habituation to one of Mutual Caring involves mindfulness (Winnicott, 1954) and self-awareness about how one is feeling in terms of his or her emotional and mental states of mind. This mindfulness has been called "going on being" (Epstein, 2009) in the context of working through problems and meditating toward a better life to unite the psyche and spirit. Similar to the concept of how routinizing better habits (for example, eating more nutritiously, getting more exercise, or meditating) are reinforced through mindfulness and one's unique personal experiences, so is the practice of working with a trusted advisor.

As one study participant found in the course of providing lessons learned services as a consultant, "Oh yeah, in the meeting you just see them, they wouldn't look at the paper, everybody else is poring over the paper, they'd sit back and they'd start telling stories, that seemed to be the common thread" (MA, line 255).

Over and above documentation or archiving practices in databases, the value of stories stems from the meaning the story has for the storyteller, the context in which it is shared, the parties involved, and the meaning that the listeners derive from it.

Now the bad part of what's next, it's almost like Native (Indigenous Indian) [oral] stories, we don't write them down. And to be honest, I don't know how you'd do that. Like what do you capture? It'd be volumes; like you could write a book easily about it and none of us have the time to do that and if we did, we forget three quarters of it (DB, line 95).

The aforementioned quote reflects that documented lessons tend not to be read and highlights the usefulness of storytelling. For example, when a trusted advisor shares a personal story about an experiential learning from his or her past, he or she is also sharing some of his or her own vulnerabilities 


\section{Mutual Caring—Resolving Habituation Through Awareness}

and mistakes, thereby demonstrating that he or she identifies with the other person. Through this process, the listener retains meaningful memories of the story (mental snapshots) to carry forward and apply to the next project.

In summary, engaging and sharing, comfortable conversations, and selfconfidence are necessary for Mutual Caring to occur. The interactions between these variables culminate in expanding and deepening the wisdom pool. Unlike the Habituation pattern, which corresponds to unproductive and maladaptive behaviors, the Mutual Caring pattern corresponds to adaptive behaviors labeled virtuous spirals (Ropo \& Hunt, 1995) as developed through personal change management (Senge et al., 1999) in the management literature. Genuine learning happens when we openly discuss and share project mistakes, including tacit knowledge. Reinforcing the Mutual Caring pattern through developing comfortable relationships with trusted advisors enables employees to discuss relevant project management issues and concerns. Since comfortable conversations can take place with more than one trusted advisor, sharing and engaging take place between those involved in the personal network developed over time. The entire process helps develop employee self-confidence and is mutually beneficial for everyone involved. Sub-core variables supporting the core variable of Mutual Caring reinforce and strengthen each other to help develop an expanding wisdom pool of individuals who continue to share their knowledge with each other. The shared benefits of the Mutual Caring process enable and empower participants to maintain these healthy relationships.

\section{Discussion}

Various data sources, including the literature, contributed to our theoretical sensitivity in generating the core variable, main concern, and related sub-core variables. The resource-based view and situated learning theory (as reviewed earlier) helped modify and extend our analysis to promote and demote codes as well as strengthen our theoretical codes and led to our understanding of the importance of one-to-one interactions in the Mutual Caring context. Our prior conceptualizations and research on project reviews and communities of practices examined these two mechanisms as effective for sharing lessons learned, with communities of practices being more beneficial. However, in this study, we became aware of the importance of more intimate professional relationships between trusted advisors and employees (dyads as a theoretical code), which we conceptualize as Mutual Caring.

Literature dealing with the concepts of care in management, spirituality in the workplace, and workplace wellness were examined after completing data analysis to determine if they existed and if so, how they contributed to the emerging theory of Mutual Caring. These bodies of literature were meaningful given that we were guided to them by the emergent theory.

\section{Care in Management}

von Krogh's constructivist article on care in knowledge creation (1998) discussed care in management and emphasized the importance of tacit knowledge and interpersonal caring in organizations as a source of innovation. Describing knowledge as a "justified true belief" (p. 135) these "five dimensions of behavior in relationships are most important: mutual trust, active empathy, access to help, lenience in judgment, and courage. Care gives rise to these forms of behavior and to their interplay." (p. 137) Care in management is articulated to include innovative incentive plans in human resources, mentoring, expressing care as an organizational value, and training employees in care-based behaviors and project reviews.

For care to be effective, employees need to be mindful of the importance of self-compassion as they transition from maladaptive habituations. Selfcompassion enhances psychological well-being (Neff, Kirkpatrick, \& Rude, 2007). Self-compassion can facilitate creative originality, particularly among those feeling self-judgmental (Zabelina \& Robinson, 2010)

Self-compassion entails being kind and understanding toward oneself in instances of pain or failure rather than being harshly self-critical; perceiving one's experiences as part of the larger human experience rather than seeing them as isolating; and holding painful thoughts and feelings in mindful awareness rather than over-identifying with them (Neff, 2003, p. 223).

Compassion relates to care in management. Just as organizations develop vision and mission statements to focus and guide the business and employees, organizations also develop value statements to guide staff in their work and conduct. Mutual Caring could definitely be one such value for organizations to include, especially in the project management context. These practices foster the types of cultures companies strive to develop and sustain (Lencioni, 2002).

The ways in which leaders guide and employees enact healthy dialogues toward learning and sharing contribute to the organization's culture and its wisdom pool, which in turn strengthen the organization. Interpersonal dialogue is based on conversations whereby individuals determine the relationships between their respective stories as shared with each other (Tschudi, 2002). Dialogue is also referred to as a free flow of meaning between people (Bohm \& Peat, 1987).

\section{Spirituality in the Workplace}

Related, yet different topics, religion pertains to an organized system of beliefs involving rituals, symbols, and practices (Koenig, McCullough, \& Larson, 2000, p. 18) and spirituality is "the personal quest for understanding answers to ultimate questions about life, about meaning and about relationship to the sacred or transcendent" (p. 18). Similarly, 
Mutual Caring enhances a resilient and strong spirit, both intra- and interpersonally. Originating from Latin, the term spirit means, "to breathe." Breathing is our very essence and it is part of our spirit. We consider spirituality to pertain to the deepest sense of self spirituality guides our values, beliefs, and behaviors in life. After the analysis, we reflected on how Habituation results in a brittle spirit and negatively affects one's quality of life and those in the workplace.

Studies on spirituality span psychology, philosophy, education, and management. Specific to the management domain, literature exists on workplace spirituality, positive organizational behavior, and spiritual leadership (Pandey, Gupta, \& Arora, 2009). Sustainability refers to meeting "the needs of the present without compromising the ability of future generations to meet their own needs" (Brundtland, 1987, p. 8). We reflected on how Mutual Caring sustains dyads of project personnel, the project team, and the organization to create sustainable communities.

\section{Workplace Wellness}

Employees can habituate and disengage to various extents in terms of productivity, emotionally, psychologically, and socially. The ensuing interpersonal conflict and communication issues can compound workplace discord For example, habituation can impact absenteeism and presenteeism (Wang et al., 2003) and contribute to burnout Burnout and engagement are opposite ends of a continuum.

Management literature exists on employee disengagement, burnout, engagement, and work-life balance (Kahn, 1990; Maslach, 2011; Maslach \& Leiter, 2008). Burnout impacts the biological, psychological, social, and spiritual aspects of life; the spillover effects disturb both home and workplace dynamics and contribute to addictions (Ajzen, 2002; Wikler, 2008; Wright, Dunford, \& Snell, 2001). An article on the human spirit at work extended Kahn's concepts of meaningfulness, safety, and availability in terms of determinants and the mediating effects of these psychological conditions (May et al., 2004). Meaningfulness had the strongest relationship to engagement. Organizations that value care in management as a guiding principle and practices to develop effective and sustainable project management communities of dialogue, can enhance employee engagement.

\section{Language}

Different words can mean the same thing or similar words can mean different things. Language ambiguities can be minimized by clarifying what concepts and terms mean. At one point in the analysis, we considered the term "relational dynamics" as referring to the close and trusting relationship between a trusted advisor and employee. However, since Mutual Caring is mediated through awareness, this term resonated more powerfully with us than the term relational dynamics because it also connected with the concept of individuation, whereas relational dynamics did not. Relational dynamics was too broad and generic to be meaningful in this context. By using the concepts of Habituation and Mutual Caring, we intentionally steered clear of the concepts of self-care and mutual care to distinguish between Habituation and Mutual Caring. The concepts of selfcare and mutual care diluted the rich conceptualization we found within the process. For the same reason, we also used the theoretical codes individualization and individuation to distinguish between unhealthy Habituation and healthy Mutual Caring.

We also intentionally used the concept of trusted advisor. This term held greater appeal because it aptly described the faith, confidence, and reliance an employee develops and maintains in his or her relationship with another person to share project concerns and lessons learned. Some of the coded terms used by study participants, noted during the analysis were coach, mentor, and proj- ect management office. Other words considered as synonyms to the term trusted advisor include supervisor or advisor. We decided these terms did not fit because such labels can elicit positive or negative responses from individuals, based on their prior experiences; however, the term trusted advisor consistently brought to mind positive words, including healthy, supportive, and beneficial, which better fit the process we identified.

The term community of practice has an existing conceptualization in the project management literature. We preferred to use the term dyadic (as also spanning smaller clusters of individuals working closely with a trusted advisor) as a more effective way to share project learning.

\section{Contributions and Concluding Speculations}

\section{Contributions to the Field and Study Limitations}

In terms of contributions to research, this study used the Grounded Theory methodology and developed an inductive theory. In doing so, Mutual Caring is the basic social psychological process. We strived to demonstrate that Mutual Caring grabs, fits, works the data, and is modifiable. The core variable and main concern should be robust enough to stand alone. In the project management context, Mutual Caring (as it pertains to sharing and learning about project management practices) is the core variable that resolves the main concern identified from the data, that of Habituation (to unproductive and at times, maladaptive project management practices and behaviors in the interest of coping with these work demands). Habituation is counterproductive to learning and maintains the status quo. In contrast, Mutual Caring opens the door to learning and support in project management, leading to workplace well-being. Mutual Caring conceptualizes the relational dynamic pertaining to more intimate (dyadic) 


\section{Mutual Caring—Resolving Habituation Through Awareness}

interpersonal discussions at work (of the informal and fluid nature) to share understanding on project management.

This study suggests a paradigm shift away from tangible project review and communities of practice, which focus on structured and codified knowledge creation and sharing practices. Mutual Caring is an intangible resource. The study findings are aligned with the project management literature based on the resource-based view, which supports the importance of intangible resources. The findings are also aligned with situated learning theory in supporting socially constructed knowledge.

In terms of limitations, the study focused on project managers from a variety of industries, but nearly one half of the participants were from the energy sector and more males than females were interviewed. Theoretical sensitivity and theoretical codes as well as constant comparison and memoing assisted in enhancing data conceptualization. Methodologically, future research could also be structured with more of an emphasis on processual approaches versus a cross-section approach as described in this article (Sergi \& Hallin, 2011). This study develops a preliminary emergent theory. The scope of verifying and modifying the grounded theory is part of a current research proposal.

From a human resources perspective, this study has implications for employee wellness and productivity. Senior executives could consider adding Mutual Caring as a core value to their corporate values and exemplify and communicate expectations of staff interactions. Through awareness and mindfulness, project leaders and employees can minimize the Habituation practices of forcing, resisting, and spinning within themselves and in relation to the processes and outputs of project review and community of practice activities. They could consider the value of dyadic relationships through Mutual Caring and its related sub-variables (engaging/sharing, comfortable conversations, trusted advisor, and wisdom pool) to share informal and tacit knowledge. Leaders should be mindful that the transition from Habituation to Mutual Caring could be difficult because of fears and concerns related to change and the emotions these changes evoked. With patience and tact, leaders can guide and support employees toward Mutual Caring. Practitioners also need to be respectful and allow their colleagues to experience the transition at their own pace and on their own terms. Project leaders would further benefit from encouraging staff to volunteer to be trusted advisors for other employees and for employees to strive to work with trusted advisors.

In addition to the methodological and literary contributions, the study findings have the potential to lead to future conceptual and empirical avenues of research. For example:

- Exploring concepts, such as care and spirituality in management in terms of:

- The roles of organizational and country cultures, trusted advisors, and how the roles between a mentor and mentee evolve and are cultivated

- Organizational and employee values and beliefs

- Aspects of tacit knowledge sharing

- Elements of organizational change management, organizational visions, and missions

- Incentives supporting care in management that foster organizational and employee values

- Exploring:

- How burnout and engagement relate to the theory of Mutual Caring

- How knowledge creation relates to the context of organizational innovation and competitive advantage (value)

- How social capital theory relates to care in management, and

- Employee disengagement and self-care as they pertain to employee wellness and well-being
Through this study, we found that the project management literature provided elements of the foundation on learning and sharing, but that in and of itself, this body of literature was insufficient. Examining the literature in situated learning theory and the resource-based view extended and enhanced our understanding of learning and sharing. We found that formal, structured, and codified practices of knowledge sharing were used in abundance but created challenges. Initially, we assumed that communities of practice held significant merit for knowledge sharing. Our findings revealed that in order for a deeper and more meaningful exchange of ideas and concerns about mistakes and problems on projects to occur, there is more value in working closely with a trusted advisor in a mutually caring dyadic relationship.

At the conclusion of the study, we found that our theory transcends the project management context. The ongoing discussions between the co-authors confirmed that both were able to relate the concepts from the Mutual Caring theory to other situations. They experienced Mutual Caring in the service of research discovery during the collaboration and hope that this research contributes to expanding the wisdom pool of Grounded Theory methodology, project management, and management.

\section{Acknowledgments}

The authors would like to acknowledge the generous support for this study from the Social Sciences and Humanities Research Council, and support in kind from Athabasca University and the University of Calgary. The authors also appreciate the contributions from study participants and the helpful and constructive feedback from the reviewers.

\section{References}

Ajzen, I. (2002). Residual effects of past on later behavior: Habituation and reasoned action perspectives. Personality and Social Psychology Review, 6(2), 107-122. 
Aubry, M., \& Hobbs, B. (2011). A fresh look at the contribution of project management to organizational performance. Project Management Journal, 42(1), 3-16.

Aubry, M., Hobbs, B., \& Thuillier, D. (2007). A new framework for understanding organisational project management through the PMO. International Journal of Project Management, 25(4), 328-336.

Barczak, G., Griffin, A., \& Kahn, K. B. (2009). Perspective: Trends and drivers of success in NPD practices: Results of the 2003 PDMA best practices study. Journal of Product Innovation Management, 26(1), 3-23.

Barney, J. (1991). Firm resources and sustained competitive advantage. Journal of Management, 17(1), 99-120.

Barney, J., Ketchen, D. J., \& Wright, M. (2011). The future of resource-based theory: Revitalization or decline? Journal of Management, 37(5), 1299-1315.

Barney, J. B. (2001). Resource-based theories of competitive advantage: A ten-year retrospective on the resource-based view. Journal of Management, 27(6), 643-650.

Barney, J. B. (2007). Gaining and sustaining competitive advantage. Upper Saddle River, NJ: Pearson Education, Inc.

Barney, J. B., \& Arikan, A. M. (2001).

The resource-based view: Origins and implications. In M. A. Hitt, R. E. Freeman \& J. S. Harrison (Eds.), The Blackwell handbook of strategic management (1st ed., pp. 124-188). Malden, MA: Blackwell Publishers Ltd.

Benoliel, J. Q. (1996). Grounded theory and nursing knowledge. Qualitative Health Research, 6(3), 406-428.

Besner, C., \& Hobbs, J. B. (2006). The perceived value and potential contribution of project management practices to project success. Project Management Journal, 37(3), 37-48.

Blumer, H. (1986). Symbolic interactionism: Perspective and method. Berkeley, CA: University of California Press.

Bohm, D., \& Peat, F. D. (1987). Dialogue and culture. New York, NY: Bantam.
Boud, D., \& Garrick, J. (1999). Understandings of workplace learning. In D. Boud \& J. Garrick (Eds.), Understanding learning at work (pp. 2-11). London, England: Routledge.

Bratton, J., Helms-Mills, J., Pyrch, T., \& Sawchuck, P. (2004). Workplace learning: A critical introduction. Aurora, ON, Canada: Garamond Press.

Bresnen, M., Edelman, L., Newell, S., Scarbrough, H., \& Swan, J. (2003). Social practices and the management of knowledge in project environments. International Journal of Project Management, 21(3), 157-166.

Brundtland, H. (1987). Report of the World Commission on Environment and Development: Our Common Future. Retrieved from http://www.undocuments.net/wced-ocf.htm

Coleman, J. S. (1988). Social capital in the creation of human capital. American Journal of Sociology, 94(Supplement), S95-S120.

Côté, J. E., \& Schwartz, S. J. (2002). Comparing psychological and sociological approaches to identity: Identity status, identity capital, and the individualization process. Journal of Adolescence, 25(6), 571-586.

De Long, D. W., \& Fahey, L. (2000).

Diagnosing cultural barriers to knowledge management. Academy of Management Executive, 14(4), 113-127. doi: 10.5465/AME.2000.3979820

Dey, I. (1999). Grounding grounded theory: Guidelines for qualitative research. London, England: Academic Press.

Duarte, D. L., \& Snyder, N. T. (2011). Mastering virtual teams: Strategies, tools, and techniques that succeed: Hoboken, NJ: John Wiley \& Sons.

Egbu, C. O. (2004). Managing knowledge and intellectual capital for improved organizational innovations in the construction industry: An examination of critical success factors. Engineering Construction and Architectural Management, 11(5), 301-315.

Eisenhardt, K., \& Santos, F. (2000). Knowledge-based view: A new theory of strategy? In A. Pettigrew, H. Thomas, \& R. Whittington (Eds.), Handbook of strategy and management (1st ed., pp. 139-162). London, England: Sage Publications.

Elliott, N., \& Lazenbatt, A. (2004).

How to recognise a 'quality' grounded theory research study. The Australian Journal of Advanced Nursing: A Quarterly Publication of the Royal Australian Nursing Federation, 22(3), 48-52.

Epstein, M. (2009). Going on being: Life at the crossroads of Buddhism and psychotherapy. Somerville, MA: Wisdom Publications.

Fenwick, T. (2006). Toward enriched conceptions of work learning: Participation, expansion, and translation among individuals with/in activity. Human Resource Development Review, 5(3), 285-302.

Foss, N. J. (1996). Knowledge-based approaches to the theory of the firm: Some critical comments. Organization Science, 7(5), 470-476.

Foss, N. J. (Ed.). (1997). Resources, firms, and strategies: A reader in the resourcebased perspective (1st ed.). Oxford, UK: Oxford University Press.

Garrety, K., Robertson, P. L., \& Badham, R. (2004). Integrating communities of practice in technology development projects. International Journal of Project Management, 22(5), 351-358. doi: 10.1016/j.ijproman.2003.08.003

Gherardi, S. (2009). Introduction: The critical power of the "practical lens." Management Learning, 40(2), 115-128.

Glaser, B. G. (1965). The constant comparative method of qualitative analysis. Social Problems, 12(4), 436-445.

Glaser, B. G. (1978). Theoretical sensitivity: Advances in the methodology of Grounded Theory. Mill Valley, CA: Sociology Press.

Glaser, B. G. (1992). Emergence vs forcing: Basics of grounded theory analysis. Mill Valley, CA: Sociology Press.

Glaser, B. G. (1998). Doing grounded theory: Issues and discussions. Mill Valley, CA: Sociology Press.

Glaser, B. G. (2001). The Grounded Theory perspective: Conceptualization 


\section{Mutual Caring—Resolving Habituation Through Awareness}

contrasted with description. Mill Valley, CA: Sociology Press.

Glaser, B. G. (2002). Conceptualization: On theory and theorizing using grounded theory. International Journal of Qualitative Methods, 1(2), Article 3. Retrieved from http://www.ualberta. ca/ iiqm/backissues/1_2Final/html/ glaser.html

Glaser, B. G. (2011). Blocking conceptualization. The Grounded Theory Review, 10(1), 1-15. Retrieved from http://www. groundedtheoryreview.com/documents/ GTReviewvol16no12.pdf

Gongla, P., \& Rizzuto, C. R. (2001). Evolving communities of practice: IBM global services experience. IBM Systems Journal, 40(4), 842-862.

Hall, J., \& Sapsed, J. (2005). Influences of knowledge sharing and hoarding in project-based firms. In P. Love, P.S.W. Fong, \& Z. Irani (Eds.), Management of knowledge in project environments (pp. 57-79). Oxford, England: ButterworthHeinemann.

Hemetsberger, A., \& Reinhardt, C. (2006). Learning and knowledgebuilding in open-source communities: A social-experiential approach. Management Learning, 37(2), 187-214. doi: 10.1177/1350507606063442

Hernandez, C. (2009). Theoretical coding in grounded theory methodology. The Grounded Theory Review, 8(3), 51-60.

Holton, J. A. (2007). The coding process and its challenges. The SAGE Handbook of Grounded Theory (pp. 265-289). Thousands Oaks, CA: SAGE Publications Ltd.

Jugdev, K., \& Mathur, G. (2006). Project management elements as strategic assets: Preliminary findings. Management Research News, 29(10), 604-617.

Jugdev, K., \& Mathur, G. (2012). Classifying project management resources by complexity and leverage. International Journal of Managing Projects in Business, 5(1), 105-124.

Jugdev, K., \& Mathur, G. (2013). Bridging situated learning theory to the resource-based view of project management. International Journal of Managing Projects in Business, 6(4), 633-653.

Jugdev, K., Mathur, G., \& Fung, T. (2007). Project management assets and their relationship with the project management capability of the firm. International Journal of Project Management, 25(6), 560-568.

Kahn, W. A. (1990). Psychological conditions of personal engagement and disengagement at work. Academy of Management Journal, 33(4), 692-724.

Kamara, J. M., Augenbroe, G., Anumba, C. J., \& Carrillo, P. M. (2002). Knowledge management in the architecture, engineering, and construction industry. Construction Innovation, 2(1), 53-67. doi: 10.1108/14714170210814685

Keil, M., \& Montealegre, R. (2000). Cutting your losses: Extricating your organization when a big project goes awry. Sloan Management Review, 41(3), 55-68.

Koenig, H. G., McCullough, M., \& Larson, D. B. (2000). Handbook of religion and health. New York, NY: Oxford University Press.

Kotnour, T. G., \& Kurstedt, H. A. (2000). Understanding the lessons-learned process. International Journal of Cognitive Ergonomics, 4(4), 311-330. Kransdorff, A. (1996). Viewpoints: Using the benefits of hindsight-the role of post-project analysis. Managerial Auditing Journal, 11(4), 42-48.

Kransdorff, A., \& Williams, R. (1999). Swing doors and musical chairs. Business Horizons, 42(3), 27-32.

Larson, E. W., \& Gray, C. F. (2014). Project management: The managerial process (6th ed.). New York, NY: McGraw-Hill.

Lave, J. (1993). The practice of learning. In S. Chaiklin \& J. Lave (Eds.), Understanding practice: Perspectives on activity and context. Cambridge, England: Cambridge University Press.

Lave, J., \& Wenger, E. (1991). Situated learning: Legitimate peripheral participation. New York, NY: Cambridge University Press.

Lencioni, P. M. (2002). Make your values mean something. Harvard Business

Review, 80(7), 113-117.

Leonard, D., \& Sensiper, S. (1998). The role of tacit knowledge in group innovation. California Management Review, 40(3), 112-132.

Lesser, E. L., \& Storck, J. (2001).

Communities of practice and organizational performance. IBM Systems Journal, 40(4), 831.

Liebowitz, J., \& Megbolugbe, I. (2003). A set of frameworks to aid the project manager in conceptualizing and implementing knowledge management initiatives. International Journal of Project Management, 21(3), 189-198. doi: 10.1016/s0263-7863(02)00093-5

Lipshitz, R., Popper, M., \& Friedman, V. J. (2002). A multifacet model of organizational learning. The Journal of Applied Behavioral Science, 38(1), 78-98.

Lundin, J., \& Nuldén, U. (2007). Talking about tools: Investigating learning at work in police practice. Journal of Workplace Learning, 19(4), 222-239. doi:10.1108/13665620710747915

Maslach, C. (2011). Burnout and engagement in the workplace: New perspectives. The European Health Psychologist, 13(3), 44-47.

Maslach, C., \& Leiter, M. P. (2008). The truth about burnout: How organizations cause personal stress and what to do about it: San Francisco, CA: Jossey-Bass.

Mathur, G., Jugdev, K., \& Fung, T. (2007). Intangible project management assets as determinants of competitive advantage. Management Research News, 30(7), 460-475.

Mathur, G., Jugdev, K., \& Fung, T. (2013). Project management assets and project management performance outcomes: Exploratory factor analysis. Management Research Review 36(2), 112-135.

May, D. R., Gilson, R. L., \& Harter, L. M. (2004). The psychological conditions of meaningfulness, safety and availability and the engagement of the human 
spirit at work. Journal of Occupational and Organizational Psychology, 77(1), 11-37.

Morris, P. W. (2013). Reconstructing project management reprised: A knowledge view. Project Management Journal, 44(5), 6-23.

Nahapiet, J., \& Ghoshal, S. (1998). Social capital, intellectual capital, and the organizational advantage. In E. L. Lesser (Ed.), Knowledge and social capital: Foundations and applications (1st ed., Vol. 1, pp. 119-157). Boston, MA: Butterworth \& Heinemann.

Neff, K. D. (2003). The development and validation of a scale to measure self-compassion. Self and Identity, 2(3), 223-250.

Neff, K. D., Kirkpatrick, K. L., \& Rude, S. S. (2007). Self-compassion and adaptive psychological functioning. Journal of Research in Personality, 41(1), 139-154.

Newell, S., Bresnen, M., Edelman, L., Scarbrough, H., \& Swan, J. (2006). Sharing knowledge across projects: Limits to ICT-led project review practices. Management Learning, 37(2), 167-185. doi:10.1177/1350507606063441

Nonaka, I., Toyama, R., \& Konno, N. (2000). SECI, Ba and Leadership: A unified model of dynamic knowledge creation. Long Range Planning, 33(1), 5-34. O'Dell, C., \& Grayson, C. J. (1998). If only we knew what we know: Identification and transfer of internal best practices. California Management Review, 40(3), 154-174.

Pandey, A., Gupta, R. K., \& Arora, A. P. (2009). Spiritual climate of business organizations and its impact on customers' experience. Journal of Business Ethics, 88(2), 313-332. doi: 10.1007/ s10551-008-9965-z

Papke-Shields, K. E., Beise, C., \& Quan, J. (2010). Do project managers practice what they preach, and does it matter to project success? International Journal of Project Management, 28(7), 650-662.

Patanakul, P., Iewwongcharoen, B., \& Milosevic, D. (2010). An empirical study on the use of project management tools and techniques across project life-cycle and their impact on project success. Journal of General Management, 35(3), 41-65.

Peteraf, M. (1993). The cornerstones of competitive advantage: A resourcebased view. In N. Foss (Ed.), Resources, firms, and strategies: A reader in the resource-based perspective (1st ed., Vol. 1, pp. 187-203). Oxford, England: Oxford University Press.

Project Management Institute. (2013). A guide to the project management body of knowledge (PMBOK ${ }^{\circledast}$ guide) - Fifth edition. Newtown Square, PA: Author.

Ray, G., Barney, J. B., \& Muhanna, W. A. (2004). Capabilities, business processes, and competitive advantage: Choosing the dependent variable in empirical tests of the resource-based view. Strategic Management Journal, 25(1), 23-37.

Roderick, C. (2009). Learning classic grounded theory: An account of the journey and advice for new researchers. The Grounded Theory Review, 8(2), 49-63. Retrieved from http://ezproxy.lib.ucalgary.ca:2048/login?url=http://search. ebscohost.com/login.aspx?direct=true \&d $\mathrm{b}=$ sih\&AN=43884323\&site=ehost-live

Ron, N., Lipshitz, R., \& Popper, M. (2006). How organizations learn: Postflight reviews in an F-16 fighter squadron. Organization Studies, 27(8), 1069-1089.

Ropo, A., \& Hunt, J. G. J. (1995). Entrepreneurial processes as virtuous and vicious spirals in a changing opportunity structure: A paradoxical perspective. Entrepreneurship Theory and Practice, 19(3), 91-111.

Schwartz, S. J., Côté, J. E., \& Arnett, J. J. (2005). Identity and agency in emerging adulthood two developmental routes in the individualization process. Youth \& Society, 37(2), 201-229.

Senge, P., Kleiner, A., Roberts, C., Ross, R., Roth, G., Smith, B., \& Guman, E. C. (1999). The dance of change: The challenges to sustaining momentum in learning organizations. Performance Improvement, 38(5), 55-58.

Sense, A. J. (2003). Learning generators: Project teams reconceptualized. Project
Management Journal, 34(3), 4-12. doi: 417636411

Sense, A. J. (2004). An architecture for learning in projects? Journal of Workplace Learning, 16(3/4), 123-145. doi: 667004071

Sense, A. J. (2008). Conceptions of learning and managing the flow of knowledge in the project-based environment. International Journal of Managing Projects in Business, 1(1), 33-48. doi: 1574745671

Sense, A. J., \& Badham, R., J. (2008). Cultivating situated learning within project management practice: A case study exploration of the dynamics of projectbased learning. International Journal of Managing Projects in Business, 1(3), 432-438. doi: 1550300201

Sergi, V., \& Hallin, A. (2011). Thick performances, not just thick descriptions: The processual nature of doing qualitative research. Qualitative Research in Organizations and Management: An International Journal, 6(2), 191-208.

Snider, K. F., \& Nissen, M. E. (2003). Beyond the body of knowledge: A knowledge-flow approach to project management theory and practice. Project Management Journal, 34(2), 4-12.

Söderlund, J. (2002). On the development of project management research: Schools of thought and critique. International Project Management Journal, 8(1), 20-31.

Söderlund, J. (2004). Building theories of project management: Past research, questions for the future. International Journal of Project Management, 22(3), 183-191.

Starks, H., \& Trinidad, S. B. (2007). Choose your method: A comparison of phenomenology, discourse analysis, and grounded theory. Qualitative Health Research, 17(10), 1372-1380.

Staw, B. M. (1981). The escalation of commitment to a course of action. Academy of Management Review, 577-587.

Tschudi, F. (2002). Bohemian dialogue in groups: An analogue for therapy? Paper presented at the Second International Conference on the Dialogical Self, Ghent, 
Mutual Caring—Resolving Habituation Through Awareness

BE. Retrieved from http://web.lemoyne. edu/ hevern/isds/conference_ghent/ home.html

von Krogh, G. (1998). Care in knowledge creation. California Management Review, 40(3), 133-153.

Wang, P. S., Beck, A., Berglund, P., Leutzinger, J. A., Pronk, N., Richling, D., Schenk, T.W., Simon, G., Stang, P., \& Ustun, T. B. (2003). Chronic medical conditions and work performance in the health and work performance questionnaire calibration surveys. Journal of Occupational and Environmental Medicine, 45(12), 1303-1311.

Weick, K. E., \& Quinn, R. E. (1999). Organizational change and development. Annual Review of Psychology, 50(1), 361-386.

Wenger, E. (2004). Knowledge management as a doughnut: Shaping your knowledge strategy through communities of practice. Ivey Business Journal, 68(3), 1-8.

Wernerfelt, B. (1984). A resource-based view of the firm. Strategic Management Journal, 5(2), 171-180.

White, D., \& Fortune, J. (2002). Current practices in project management: An empirical study. International Journal of Project Management, 20(1), 1-11.
Wikler, A. (2008). On the nature of addiction and habituation. British Journal of Addiction to Alcohol \& Other Drugs, 57(2), 73-79.

Williams, T. (2008). How do organizations learn lessons from projectsand do they? IEEE Transactions on Engineering Management, 55(2), 248-266. doi: 10.1109/TEM.2007.912920 Winnicott, D. W. (1954). Mind and its relation to the psyche-soma. British Journal of Medical Psychology, 27(4), 201-209.

Wright, P. M., Dunford, B. B., \& Snell, S. A. (2001). Human resources and the resource-based view of the firm. Journal of Management, 27(6), 701-721. doi: 10.1177/014920630102700607

Yin, R. K. (2009). Case study research: Design and methods (4th ed.). Los Angeles, CA: Sage.

Zabelina, D. L., \& Robinson, M. D. (2010). Don't be so hard on yourself: Self-compassion facilitates creative originality among self-judgmental individuals. Creativity Research Journal, 22(3), 288-293.

Kam Jugdev, PhD, PMP, is a Professor of Project Management and Strategy in the Faculty of Business at Athabasca
University, St. Albert, Alberta, Canada. She develops and teaches project management courses at both the undergraduate and graduate levels. Her federally funded research includes Social Sciences and Humanities Research Council grants. Kam's research program spans burnout in project managers, lessons learned, project management tools and techniques, project success/failure, and project management as a source of competitive advantage. She may be contacted atkamj@athabascau.ca

Paul Wishart, MA, PhD, is an Adjunct Assistant Professor in the Faculty of Medicine at the University of Calgary, Calgary, Alberta, Canada, a Member Scholar of the International Institute for Qualitative Methodology, and a Grounded Theory consultant. His current research interests and expertise lie in the area of grounded theory, in generating relevant theory about what is going on in the data. He has applied his grounded theory expertise in a variety of contexts and disciplines and also develops grounded theory workshops for graduate students, faculty, and clinicians, as well as providing spiritual care for the researchers. He may be contacted at pmwishart@shaw.ca 